\title{
Hegel, Habermas e a modernidade
}

\author{
Luiz Repa \\ luizrepa@uol.com.br \\ Universidade Federal do Paraná, Curitiba, Paraná, Brasil
}

resumo 0 artigo procura mostrar os principais motivos que levam Habermas a atribuir a Hegel o posto de inaugurador do discurso filosófico da modernidade. Retomando duas críticas distintas a essa tese, reivindicando tal posto para Kant, busca-se em seguida sustentar que, para Habermas, um conceito adequado de modernidade tem de ser ao mesmo tempo uma crítica da modernidade.

palavras-chave Habermas; Hegel; modernidade; reconhecimento intersubjetivo

Entre todos os representantes da chamada "grande filosofia", Hegel é sem dúvida aquele a que Habermas mais dedicou ensaios e capítulos em suas reconstruções teóricas. Como editor do escritos políticos de Hegel, em 1966, buscou relacionar a atividade do publicista e redator de jornal com a atividade do pensador sistemático (HABERMAS, 1971b). Poucos anos antes, ele já havia retomado a crítica hegeliana à Revolução Francesa, em oposição à tese de J. Ritter de que Hegel seria o filósofo da revolução por excelência (HABERMAS, 1971a). Poucos anos depois, abre uma nova linha de interpretação do jovem Hegel, mais exatamente do período de Jena, que serviria de base para sua própria reformulação da teoria crítica, apoiando-se na distinção entre trabalho e interação (HABERMAS, 1968). Na mesma época, por volta de 1968, principia seu livro Conhecimento e interesse com uma análise da Fenomenologia do espírito (HABERMAS, 1973). Em 1974, discute a atualidade da tese hegeliana de que a sociedade moderna forma sua identidade a partir do Estado constitucional (HABERMAS, 
1976). Mas é só em 1985 que Habermas publica sua leitura mais ampla de Hegel, considerando-o o filósofo que inaugura o discurso filosófico da modernidade (HABERMAS, 1988). Em seguida, no âmbito das discussões sobre a ética do discurso, alinhava e enfrenta as objeções hegelianas contra a moral kantiana (HABERMAS, 1991). A esses sete "encontros com Hegel”, poderíamos somar um tantos outros, só que bem mais ligeiros.

Uma tal recorrência, porém, não traduz a intenção de renovar o pensamento hegeliano. Longe disso, mal encontramos uma avaliação mais detida sobre a dialética, para dar um exemplo óbvio. Não se trata de reconstruir nem de atualizar a teoria hegeliana a fim de que seus objetivos pudessem ser alcançado com premissas modificadas. Com exceção das passagens dedicadas ao jovem Hegel, ao período "intersubjetivista", por assim dizer, todas as demais abordagens são marcadamente críticas, mesmo quando se busca qualificá-lo como o primeiro filósofo a conceitualizar a modernidade.

Por outro lado, é preciso observar que nessas abordagens se atribui à filosofia hegeliana quase sempre a posição de questionamentos incontornáveis para o pensamento contemporâneo. Pode-se dizer que são esses questionamentos e não as suas soluções o que, para Habermas, poderia ainda permanecer como herança genuína da filosofia hegeliana, salvo, mais uma vez, os primeiros esboços sobre o conceito de reconhecimento recíproco ${ }^{1}$. Pois as soluções ou as tentativas de solucionar os problemas colocados pela primeira vez por Hegel vão se inspirar muito mais em Kant, isto é, em um conceito de razão complexo e procedimental, calcado, porém, não em uma teoria das faculdades cognitivas, mas sim na ação comunicativa e na teoria do discurso. Uma espécie de aliança entre Kant e o jovem Hegel forneceria assim os meios para uma alternativa à solução proposta pelo Hegel maduro.

Embora todos esses questionamentos postos por Hegel tenham especificidades próprias, eles remetem uns aos outros e desembocam em geral em uma teoria da modernidade. Eu pretendo aqui relembrar primeiramente os principais motivos que levam então Habermas a atribuir a Hegel o posto de inaugurador do discurso filosófico da modernidade. Em seguida tentarei mostrar que duas críticas a essa tese, reivindicando tal posto para Kant, passam por cima do que é essencial a Habermas, isto é, que um conceito adequado de modernidade tem de ser 
ao mesmo tempo uma crítica da modernidade. Por fim, pretendo ao menos indicar como Habermas encaminha uma solução para essa crítica, sem ter de enfrentar os dilemas do próprio Hegel.

Segundo Habermas, Hegel teria sido o primeiro filósofo a estabelecer a constelação conceitual entre modernidade, consciência histórica e razão. Primeiramente, a modernidade e todas as expressões correlatas não se designam apenas uma época, mas acima de tudo trazem consigo a expressão da consciência de ser época, de ser um tempo presente que se diferencia do passado por rupturas, e que desse modo é posto sob pressão do futuro. Os tempos modernos trazem consigo sempre o novo, medido por sua referência negativa não só às tradições mais arraigadas, mas também ao passado mais recente. Por isso os novos tempos designam para Hegel, antes de tudo, a Revolução francesa e o Iluminismo.

A ruptura com o passado e o olhar para as conseqüências futuras formam uma tal consciência de tempo que agora todas as instâncias do saber e da ação precisam ser fundamentadas sem o recurso a tradições exemplares. Hegel liga então a consciência histórica radicalmente nova que emerge na modernidade e como modernidade à questão crucial de a contemporaneidade sempre ter de fundamentar-se a partir de si mesma, de buscar sempre em si mesma os seus critérios de orientação normativa. Essa necessidade de autocertificação ou autofundamentação da modernidade, Hegel a teria entendido como tarefa de sua filosofia. Abarcar em pensamentos a época presente é compreender por que e como a modernidade pode resolver a questão de orientar-se normativamente a partir do seu próprio solo.

A consciência histórica de época e a necessidade de autocertificação formam os dois primeiros motivos que, para Habermas, impelem a filosofia hegeliana a articular em conceitos seu próprio tempo, e, com isso, articular pela primeira vez, no âmbito do discurso filosófico, um conceito de modernidade. Mas essa articulação só se inteira à medida que o assunto próprio da filosofia, a razão, é religado à necessidade histórica de autocertificação. Porque o processo de esclarecimento no séc. XVIII desvalorizou a tal ponto as autoridades baseadas na tradição, a modernidade só pode encontrar legitimidade a partir de discursos racionais, a partir da crítica da razão. 
Por isso a crítica kantiana da razão tem uma posição chave para a compreensão hegeliana da modernidade. Isto é, Hegel, em uma visão retrospectiva, compreende que a filosofia kantiana constitui, como ponto de fuga do processo de esclarecimento do séc. XVIII, a "autocompreensão decisiva da modernidade" (HABERMAS, 1988, p. 30; cf. também HABERMAS, 1998). Os traços essenciais da época se reproduzem nas três críticas como em um espelho. A crítica da razão explicaria as condições de possibilidade da ciência da natureza; a crítica da razão prática explicaria como as pessoas adquirem autonomia sob leis geradas por elas próprias, e a crítica do juízo explicaria, por fim, as condições subjetivas de uma experiência estética desembaraçada do contexto religioso. A filosofia kantiana expressa assim o conteúdo normativo da modernidade, centrado nas idéias de crítica e reflexão, de autonomia e auto-realização.

A diferenciação de ciência, moral e arte, que mais tarde Weber definiria como marca da modernidade cultural, como resultado do processo de racionalização, teria sido visto por Hegel como fundamentada pela filosofia kantiana, ao tomar a razão como única fonte de critérios para a resposta às questões sobre a verdade, a justiça e o gosto. O que Kant não teria percebido é que a diferenciação da razão imposta pela própria razão não era apenas apreendida de maneira reflexiva pelo sujeito do conhecimento e da ação, mas já constitui uma realidade institucional com conseqüências para a reprodução da cultura e da sociedade como um todo. A visão retrospectiva de Hegel sobre Kant é definida pelo discernimento de que a modernidade já se encontra em racionalização, de que a razão já criou formas institucionais na vida cultural e social, e que agora podemos compreender essas formas retrospectivamente, reconstruindo a razão na história. Dessa maneira, Hegel teria estabelecido o laço entre modernidade, consciência de época e razão.

É por essa perspectiva que se deve entender também o fato de a conceitualização da modernidade coincidir com uma crítica da modernidade, vale dizer, com uma crítica da filosofia da reflexão e, especialmente, da filosofia kantiana. Pois o conteúdo normativo da modernidade é instaurado a partir e por meio do princípio da subjetividade. O sujeito do conhecimento e da ação, no qual se centra o conceito de razão, fornece por si próprio as condições de fundamentação de que necessita uma modernidade desprovida de orientações tradicionais. 
Mas esse mesmo princípio, que deve ser salvaguardado, é também unilateral, incapaz de perceber que as diferenciações da razão devem aparecer como cisões uma vez transpostas para o contexto das relações éticas imediatas. O ganho que a crítica da razão representou é contraposto, assim, à perda da força unificadora da qual se nutria outrora a religião. O princípio da subjetividade se mostra incapaz de regenerar, por meio da razão, a força de unificação, sem o que as novas instituições modernas, que corporificam o conteúdo normativo da modernidade, passam imediatamente a ter efeitos desagregadores.

Segundo Habermas, tais efeitos de desagregação são compreendidos também, e da maneira mais evidente, nas instituições do direito formal burguês, da economia de mercado, na máquina burocrática do Estado. Sob o impacto da leitura da economia política, Hegel transpôs para a filosofia a tematização dos efeitos desagregadores da autonomização da esfera de produção e troca em relação ao contexto das relações éticas. A diferenciação entre sociedade civil, regulada pela economia de mercado, e o Estado, também aponta para os estudos posteriores de Weber sobre a modernização social.

Em resumo, Hegel teria inaugurado o discurso filosófico da modernidade ao levar a sério a consciência de tempo, inscrevendo-a na necessidade de autocertificação, que deve partir do conteúdo normativo liberado pelo princípio da subjetividade, mas ao mesmo tempo refletindo sobre as conseqüências desagregadoras que esse mesmo princípio acarreta ao se corporificar institucionalmente na cultura e na sociedade. A necessidade da filosofia surge justamente como necessidade imposta pelas cisões modernas. A modernidade estaria desde o início presa a uma dialética do esclarecimento que ao mesmo tempo emancipa e cria novas formas de repressão.

A razão reprime porque se fundamenta na estrutura da auto-referência de um sujeito cognoscente que faz de si mesmo e de tudo ao redor objeto de conhecimento e ação. O interesse de Habermas pelo Hegel filósofo da modernidade reside também ou sobretudo aí. O conceito dos tempos modernos é remetido desde o início à crítica da filosofia do sujeito, de tal modo que o conteúdo normativo alicerçado primeiramente por essa filosofia poderia ser desenvolvido não mais a partir da subjetividade enquanto tal, mas das estruturas intersubjetivas em que se forma o sujeito individual. 
Se essa caracterização está correta, apesar da forte simplificação, podese abordar a seguinte passagem do Discurso filosófico da modernidade, sentida como no mínimo "questionável" por muitos... kantianos. "Kant expressa o mundo moderno em um edifício de pensamentos. De fato, isto significa apenas que na filosofia de Kant se refletem os traços essenciais da época como em um espelho, sem que Kant tivesse conceituado a modernidade enquanto tal. Só por uma visão retrospectiva Hegel pode entender a filosofia de Kant como auto-interpretação decisiva da modernidade; Hegel visa conhecer também o que restou de impensado nessa expressão mais refletida da época: Kant não sente como cisões as diferenciações no interior da razão, nem as divisões formais no interior da cultura, nem em geral a dissociação dessas esferas. (...) Agora a questão é saber se da subjetividade e da consciência de si podem obter-se critérios próprios ao mundo moderno e que sirvam ao mesmo tempo para orientar-se nele; mas isso significa também que possam ser aptos para a crítica de uma modernidade em conflito consigo mesma." (HABERMAS, 1988, pp. 30-31)

Ora, por essa passagem se torna evidente que é antes de tudo a problematização das cisões modernas que explicaria a perspectiva de por que o tema da autocertificação moderna não culmina, no essencial, com o próprio Kant, uma vez que ele representaria "a auto-interpretação decisiva da modernidade”. Certamente essa expressão é ambígua, já que uma auto-interpretação decisiva da modernidade deveria significar conceitualizar a modernidade enquanto tal. Além disso, dificilmente se poderia negar a Kant duas determinações que são atribuídas ao conceito hegeliano de modernidade. Primeiramente, Kant compreende sua época como radicalmente nova, a saber, como a "época da crítica a que tudo tem de se submeter", ou seja, uma época que se compreende a si mesma como ruptura com as tradições. Além disso, não se poderia ignorar que a filosofia kantiana desconhece as necessidades que surgem com suas próprias diferenciações. Ela reporia a unidade da razão em um alto nível de reflexão, estabelecendo passagens entre os domínios diferenciados.

Com esses argumentos, mas no interior de estratégias bem diferentes, Herbert Schnädelbach e Ricardo Terra reivindicam, contra Habermas, a caracterização de Kant como filósofo da modernidade. Ambos apontam também para o caráter problemático das "cisões" como critério para a 
compreensão correta da modernidade. Schnädelbach escreve o seguinte em seu ensaio "Kant, o filósofo da modernidade": "Uma coisa é certa: Kant não entendeu aquilo a ser distinguido na razão e na realidade como resultado de 'cisões' e não pôs a necessidade provocada por isso em relação a uma 'época histórica'. Se se coloca isto como critério, Kant de fato 'não conceitualizou a modernidade como tal'. Mas se trata do critério correto? (...) Ao conceitualizar a modernidade como resultado de cisão e alienação, Hegel, os jovens hegelianos e Habermas colocam-na na perspectiva de sua superação real, e esta não é outra coisa que uma superação (Aufhebung) da alienação na "reconciliação"” (SCHNÄDELBACH, 2000, pp. 30-32).

Em uma perspectiva bem diferente, Ricardo Terra parte dos resultados da teoria habermasiana da racionalidade comunicativa, para mostrar justamente filiação desta com o kantismo, a qual o texto do Discurso parece querer ocultar. Escreve Ricardo Terra: “Ora, se nos concentrarmos por um momento na questão da ampliação da razão, veremos que Habermas, com o paradigma da comunicação, radicaliza a perspectiva kantiana, renunciando a uma racionalidade substancial e confiando numa racionalidade procedimental. Com a diferença - esta sim decisiva - de que, no lugar de uma teoria das faculdades de uma filosofia da consciência, Habermas propõe uma teoria da argumentação, com a diferenciação em discurso teórico, discurso prático ético-jurídico e crítica estética. (...) É certo que Kant não tematizou as cisões, não sofreu o impacto da economia política, não previu as tensões sociais, mas também não tentou superar os dilemas da modernidade numa 'totalidade mística' ou numa revolução salvadora. Apesar da cisão efetiva das esferas, a razão, para Kant não perde por isso sua unidade. Ao contrário, é o conceito mesmo de unidade da razão que se altera" (TERRA, 2003, p. 22).

Embora bem mais precisa em relação a Habermas, essa interpretação explicita a insuficiência do tema das cisões, e sugere, como Schnädelbach, seu caráter problemático quando pensado em seu vínculo com a reconciliação da modernidade em uma "totalidade mística".

Ao contrário, para Habermas, o tema das cisões é o que torna a exigência de autocertificação moderna ainda mais reflexiva. Com ele, a modernidade, caracterizada por Kant como a época da crítica, tem de se tornar para si mesma também época de crise. Ou seja, estaria dada a 


\section{8}

perspectiva para um diagnóstico de época que se volta para fenômenos patológicos suscitados com a própria modernidade. A questão imediata que se põe é se, ao contrário do que pensa Schnädelbach, por cisão devese entender unicamente a quebra da unidade originária que requer por força própria uma auto-reconciliação. Certamente Habermas concorda explicitamente que essa idéia pressionou o Hegel maduro - e justamente por isso ele foi lançado para fora da constelação entre consciência de época, modernidade e racionalidade, constelação que ele mesmo estabelecera. Mas por cisão deve-se entender também a primeira expressão de uma patologia moderna que se refere à quebra e por fim à reificação das relações de reconhecimento recíproco: "Desde o fim do século XVIII, o discurso da modernidade teve um único tema, ainda que sob títulos sempre renovados: o enfraquecimento das forças de coesão social, a privatização e a cisão, em suma: aquelas deformações de uma práxis cotidiana racionalizada de modo unilateral, que provocam a necessidade de um equivalente ao poder de unificação da religião" (HABERMAS, 1988, p. 166). É justamente por isso que, na passagem citada anteriormente, Habermas põe a questão de se o princípio da subjetividade é apto para fornecer critérios também para uma crítica da modernidade. Evidentemente, para ele próprio, a resposta a essa "questão hegeliana" só poderia ser negativa.

Segundo Habermas, Hegel poderia ter dado um certo rumo à dialética do esclarecimento, explicitando como o princípio de subjetividade é tributário de relações de reconhecimento recíproco que desde sempre serve de base para as relações cognitivas, éticas e estéticas do sujeito individual. Para Habermas, ele tinha os mecanismos para esboçar uma semelhante linha teórica, já que no seu período de juventude pensara o poder de unificação das relações de reconhecimento dadas na eticidade natural das comunidades políticas como a contrapartida das cisões modernas.

Mas esse rumo estava interditado para Hegel, pois ele entendeu, já no período de Jena, que uma tal base intersubjetiva se encontrava entrelaçada concretamente com a realidade já superada historicamente da polis grega ou das comunidades do cristianismo primitivo. A necessidade autocertificação imanente da modernidade lhe proibia o recurso a passados exemplares que de todo modo eram desmentidos pela economia e pelo estado burocrático modernos. 
Dessa maneira, Hegel tomou um caminho que, como sublinhei, termina por lançá-lo para fora da constelação que ele mesmo articulou entre consciência histórica, racionalidade e modernidade. Essa solução é caracterizada por Habermas como uma crítica à subjetividade moderna que se realiza no interior do paradigma da filosofia do sujeito. Hegel passa a compreender as cisões operadas pela subjetividade como momentos necessários do desenvolvimento do sujeito universal que recebe o nome de espírito absoluto. O macro-sujeito "espírito" se eleva acima das realizações individuais, como atividade infinita de pôr a si mesmo e retornar a si de suas objetivações, e, reconstruindo a si mesmo no saber acumulado pela arte, pela religião e pela filosofia, compreende-se como sujeito e objeto idêntico, ou seja, como sujeito absoluto.

Concomitantemente, a questão crucial da modernidade deixa de ser as cisões enquanto tais, pois elas até mesmo podem reivindicar um direito relativo na exata medida que provam o poder de unificação do absoluto. O problema incide unicamente sobre a consciência subjetiva que, atendo-se unicamente a si, teima em não se reconciliar com o curso dos tempos, com a razão já concretizada na história.

A conseqüência da filosofia do absoluto para a modernidade torna-se então patente: a atualidade perde o seu interesse, e a crítica fica embotada. Hegel teria resolvido tão bem a questão da autocertificação moderna que acaba por destituí-la de significado. Se tudo de essencial já está decidido, restando apenas reconciliar-se com as instituições modernas, então o tempo presente perde justamente o impulso que havia movido sua dialética do esclarecimento.

Como enunciado de início, o interesse da leitura de Habermas sobre a filosofia hegeliana não consiste propriamente na solução encaminhada para o problema da autocertificação da modernidade, mas no modo como ela é colocada. Isso se evidencia pelo fato de a dialética do esclarecimento montada por Hegel servir de parâmetro para a reconstrução do discurso filosófico da modernidade. Ou seja, trata-se de seguir a linha daqueles que pretendem dar continuidade a esse discurso pela via inaugurada por Hegel, isto é, buscando criticar a modernidade a partir dela mesma, ou que pretendem saltar para fora dela, por meio de uma crítica radical da razão. A primeira linha, representada pelos jovens hegelianos e 
que incorpora a tradição de pensamento da teoria crítica, será aquela a que se filia o próprio Habermas, em contraposição à segunda, chamada de pós-moderna, e principiada por Nietzsche.

Não vou me deter na análise dessas duas linhas do discurso. Interessame sobretudo verificar, ainda que sumariamente, de que modo Habermas pretende ainda buscar uma alternativa no interior do registro do questionamento hegeliano. Evidentemente, não se trata de forma alguma de resolver o problema das cisões modernas em uma totalidade, seja em que instância for, como sugere Schnädelbach. Em vez disso, trata-se, como destaca Ricardo Terra, de radicalizar o conceito kantiano de razão, isto é, procedimental e diferenciado em três dimensões, com base em uma teoria do discurso. Porém, é preciso enfatizar, para poder fornecer os critérios normativos para uma crítica da modernidade afetada por fenômenos patológicos. Com isso, as diferenciações no interior da modernidade cultural deixam de ser o problema fundamental; problemático e patológico se torna, antes, o desequilíbrio, no interior das práticas comunicativas cotidianas, entre os momentos da razão. Pois com a modernização capitalista, ocorre uma pressão seletiva, unilateral, para uma aproveitamento cognitivo-instrumental dos potenciais de racionalidade inscritos na cultura, enfraquecendo, no âmbito da prática cotidiana, as dimensões prático-morais e estético-expressiva (cf. REPA, 2008, KNEER, 1990). Consequentemente, a dinâmica das relações de entendimento e reconhecimento recíproco passam a sofrer, de maneira bastante sutil, uma pressão reificante, impondo a tendência para objetivar tanto o parceiro de interação quanto a si mesmo.

Habermas não parece ter dúvida de que Hegel foi o primeiro a detectar patologias sociais na modernidade. Porém, depois que o próprio Hegel encaminhou a dialética do esclarecimento para a filosofia do sujeito absoluto, depois que o conceito hegeliano de totalidade passou a suscitar aporias na vertente de esquerda do discurso moderno, ele não tem dúvida também de que a teoria social deve desenvolver um modelo crítico bem próximo do que Kant. Certamente se poderia perguntar por que afinal cisões no contexto das relações intersubjetivas, por que reificação e alienação, por que fenômenos patológicos são tão importantes para um conceito adequado de modernidade. A resposta habermasiana é a seguinte: eis algo que deve poder interessar necessariamente a todos. 
1 Sobre a apropriação habermasiana da teoria do reconhecimento do jovem Hegel, cf. CRÉAU, 1991. Cf. também o desenvolvimento dessa abordagem em Honneth, 2003.

\section{Referências bibliográficas}

CRÉAU, A. 1991. Kommunikative Vernunft als "entmystifiziertes Schicksal": Denkmotive des frühen Hegel in der Theorie von Jürgen Habermas. Frankfurt am Main: Hain.

HABERMAS, J. 1968. “Arbeit und Interaktion. Bemerkungen zu Hegels Jenenser Philosophie des Geist”. In: Technik und Wissenschaft als 'Ideologie'. Frankfurt am Main: Suhrkamp.

.1971a. "Hegels Kritik der Französischen Revolution". In:

Theorie und Praxis. Frankfurt am Main: Suhrkamp.

. 1971b. “Zu Hegels Politischen Schriften”. In: Theorie und Praxis. Frankfurt am Main: Suhrkamp.

.1973. Erkenntnis und Interesse. Frankfurt am Main: Suhrkamp.

. 1976. “Können komplexe Gesellschaften eine vernünftige

Identität ausbilden?”. In: Zur Rekonstruktion des Historischen Materialismus. Frankfurt am Main: Suhrkamp.

1988. Der philosophische Diskurs der Moderne. Frankfurt am Main, Suhrkamp.

. 1991. "Treffen Hegels Einwande gegen Kant auch auf die Diskursethik zu?”. In: Erläuterungen zur Diskursethik. Frankfurt am Main: Suhrkamp.

. 1998. "Konzeptionen der Moderne: Ein Rückblick auf zwei Traditionen”. In: Die postnationale Konstellatrion. Frankfurt am Main: Suhrkamp.

HONNETH, A. 2003. Luta por reconhecimento: a gramática moral dos conflitos sociais. São Paulo: Editora 34.

KNEER, G. 1990. Die Patologien der Moderne. Zur Zeitdiagnose in der 
Theorie des kommunikativen Handelns von Jürgen Habermas. Opladen: Westdeutscher Verlag.

REPA, L. 2008. A transformação da filosofia em Jürgen Habermas: os papéis de reconstrução, interpretação e crítica. São Paulo: Esfera Pública.

SCHNÄDELBACH, H. 2000. "Kant - der Philosoph der Moderne”. In: Philosophie in der modernen Kultur. Frankfurt: Suhrkamp.

TERRA, R. 2003. "Notas introdutórias sobre sistema e modernidade: Kant e Habermas". In: Passagens - Estudos sobre a filosofia de Kant. Rio de Janeiro: UFRJ. 